\title{
Airframe Integration Trade Studies for a Reusable Launch Vehicle
}

\author{
John T. Dorsey, Chauncey Wu, Kevin Rivers, Carl Martin, Russell Smith
}

Thermal Structures Branch, NASA Langley Research Center, Hampton, VA 23681-0001

\begin{abstract}
Future launch vehicles must be lightweight, fully reusable and easily maintained if low-cost access to space is to be achieved. The goal of achieving an economically viable Single-Stage-to-Orbit (SSTO) Reusable Launch Vehicle (RLV) is not easily achieved and success will depend to a large extent on having an integrated and optimized total system. A series of trade studies were performed to meet three objectives. First, to provide structural weights and parametric weight equations as inputs to configuration-level trade studies. Second, to identify, assess and quantify major weight drivers for the RLV airframe. Third, using information on major weight drivers, and considering the RLV as an integrated thermal structure (composed of thrust structures, tanks, thermal protection system, insulation and control surfaces), identify and assess new and innovative approaches or concepts that have the potential for either reducing airframe weight, improving operability, and/or reducing cost.
\end{abstract}

\section{INTRODUCTION}

Future launch vehicles must be lightweight, fully reusable and easily maintained if low-cost access to space is to be achieved. The Reusable Launch Vehicle Program (RLV) is a joint venture between NASA and Lockheed-Martin to develop the enabling technologies for such a vehicle. The proposed Lockheed-Martin VentureStarTM, shown in Figure 1, has a goal of reducing the cost of placing payloads into orbit by an order of magnitude (Cook, 1996). The Lockheed-Martin RLV configuration baseline is a lifting body with aerospike engines mounted aft. The vehicle must have a payload bay with a diameter of 15 feet and a nominal length of $45-60$ feet, with length running fore to aft and payload bay centerline coincident with the vehicle centerline. The economic viability of the RLV depends to a large extent on achieving target gross and empty weights of the vehicle. In order to minimize weight, innovative and integrated concepts will be required for the major airframe structural components, which include; the Thermal Protection and its Support System (TPS and TPSS), the cryogenic fuel tanks, intertank structures, engine thrust structure and control surfaces. The major airframe structural components are shown in a schematic of the RLV structural arrangement in Figure 2.

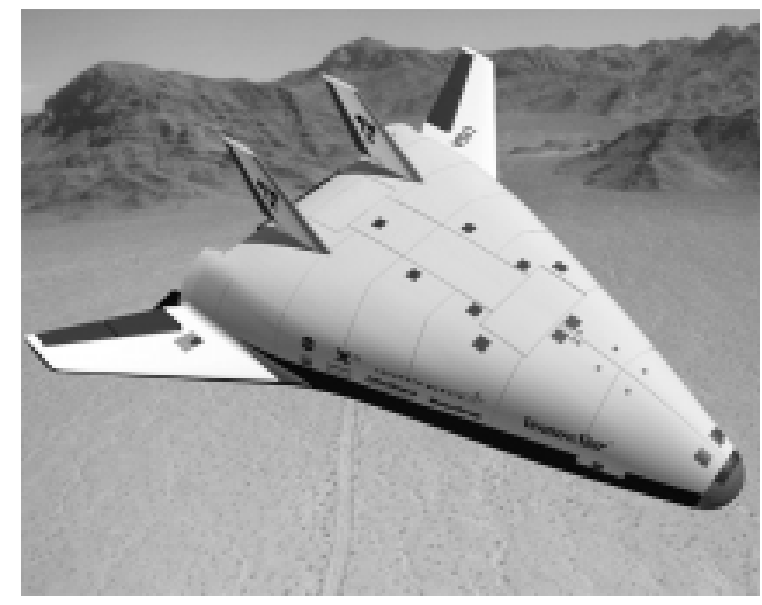

Figure 1. Lifting Body Reusable Launch Vehicle Concept. 


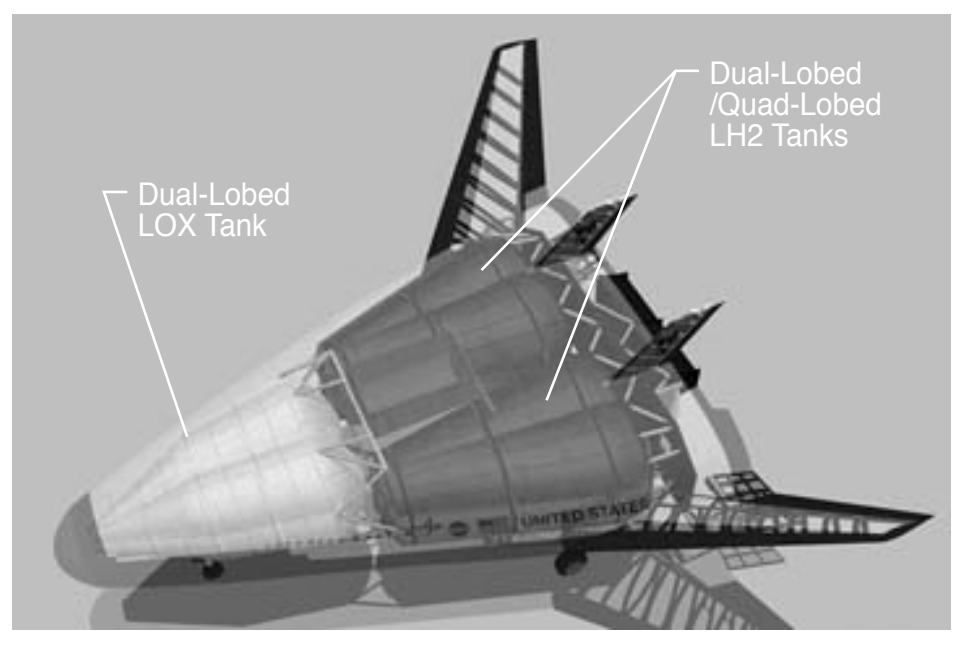

Figure 2. Lifting Body Reusable Launch Vehicle Concept.

The goal of an economically viable Single-Stage-to-Orbit (SSTO) RLV is not easily achieved and success will depend to a large extent on having an integrated and optimized total system. At the airframe structural level, this requires that the thermal/structural concepts for vehicle components be optimized as a complete system, rather than individually. The Thermal Structures Branch (TSB), in conjunction with the Vehicle Analysis Branch (VAB) at NASA Langley Research Center, is performing a number of trade studies in support of the RLV Program. The objective of each trade study falls into one of three major categories. First, to provide structural weights and parametric weight equations as inputs to configuration-level trade studies being performed by the LaRC VAB. These weights are based on structurally sized major airframe components and are of sufficient fidelity to allow major structural changes to be reflected in system-level analyses and weight statements. Second, to identify, assess and quantify major weight drivers for the RLV airframe. Third, using information on major weight drivers, and considering the RLV as an integrated thermal structure (composed of thrust structures, tanks, thermal protection system, insulation and control surfaces), identify and assess new and innovative approaches or concepts that have the potential for either reducing airframe weight, improving operability, and/or reducing cost.

\section{VEHICLE STRUCTURAL DEFINITION}

RLV configurations currently being considered by Lockheed-Martin have the following major structural components packaged within the vehicle outer mold line (OML) (see figure 2). A forward, multi-lobed liquid oxygen (LOX) tank, two multi-lobed liquid hydrogen (LH2) tanks, an intertank that connects and transfers load between the LOX and LH2 tanks and a thrust structure that integrates the aerospike engines, horizontal fins, main landing gear and tanks. Internal septums are used to connect opposing lobes of the tanks so that only membrane tension is induced in the tank walls and the septums under internal tank pressurization. The LH2 tanks are located on each side of the payload bay (which is located on the vehicle centerline). The engine thrust structure supports the aerospike engines on its aft end with the base of the LH2 tanks integrated into the forward end. The TPS protects the vehicle from the aerothermal environment induced by re-entry and forms the aeroshell conforming to the vehicle OML.

The two major structural systems addressed by the trade studies reported here, the cryogenic tanks and the TPS/TPSS, account for a significant portion of the RLV empty weight. Minimizing the TPS and TPSS unit weights are important because of the large surface area of the vehicle. The majority of the RLV internal volume is filled with the cryogenic tanks. The weight of the fuel and oxidizer contained in the cryotanks represents a significant portion of the RLV gross lift off weight (GLOW). The TPS is attached to the tanks and intertank structures through the TPSS. Depending on the tank structural concept and stiffening arrangement, the TPSS may be attached to external stiffeners, such as ring frames and longerons, or to the outer skin of a sandwich tank. Cylindrical tanks do not package efficiently within the noncircular cross-section lifting body configuration. Dual- and quad-lobed tanks are used for the lifting body shape because they package more efficiently than cylindrical tanks and can still be sized by membrane tension loads. However, there are still regions of the vehicle where large gaps exist between the tank 
walls and the vehicle OML. The weight of the TPSS required to bridge these gaps is significantly greater than the weight in regions where the tank wall and OML are closer together.

\section{TRADE STUDIES: DESCRIPTIONS AND RESULTS}

Results from a total of five different airframe-level trade studies are reported. The first two studies deal with the motivation and an approach for reducing vehicle weight by increasing cryotank packaging efficiency. The third and fourth studies illustrate the different levels of analysis fidelity required to discriminate between the structural weights of different components. The fifth study assesses several different integrated TPS/TPSS concepts.

\section{Weight Reduction Due to Changes in Primary Tank Barrel Radius}

Reductions in vehicle system weight can be achieved by maximizing the packaging efficiency (i.e., minimizing the empty space within the vehicle OML). An approach for increasing the cry tank packaging efficiency is to decrease the distance between the vehicle OML and the tank OML. In this trade study, the effect of changing the primary tank barrel radius (as the vehicle OML is held constant) on vehicle empty weight is quantified. Although the vehicle propellant volume ratio changes slightly as a result of this approach, the effect is assumed to be small at this level of analysis fidelity. Vehicle empty weight reductions will accrue from an increase in the vehicle's volumetric packaging efficiency, resulting from the increased propellant tank volume, and the net decrease in dry weight resulting from the reduction in TPS support structure weight and the increase in tank barrel weight

For SSTO launch vehicles, the vehicle empty weight is extremely sensitive to changes in weight at a local, or subsystem, level. After resizing, the vehicle empty weight decreases by 3.8 pounds for every pound of subsystem weight removed from the vehicle. This reduction in vehicle empty weight occurs because a vehicle with a lower subsystem weight may be made smaller for a given payload to orbit. In addition, because the primary tankage represents a significant portion of the vehicle volume, small changes in the packaging efficiency of the vehicle can also have a large impact on the vehicle empty weight. The baseline vehicle volumetric packaging efficiency, defined as the tankage volume divided by (vehicle OML volume - payload volume), was calculated by VAB to be 70.1 percent for this study. The vehicle empty weight sensitivity, based on preliminary weights and sizing estimates, is equal to $-2300 \mathrm{lbf}$ of empty weight per each percent increase in vehicle volumetric packaging efficiency.

At the time of this study, the baseline RLV design assumed a minimum of 9 inches for the TPS panels, TPS support structure and tank stiffening structure between the vehicle OML and tank wall OML. In this study, it is assumed that a maximum of 3 inches are required for the TPS package, and that the remaining 6 inches may be reduced or eliminated without affecting TPS operation and integration. Reducing this volume allows an increase in tank volume and vehicle packaging efficiency, as well as a proportional reduction in the TPS support structure (assumed to have a constant density of $1.8 \mathrm{lb} / \mathrm{ft} 3$ ) which occupies this volume. The entire LOX tank barrel, and 61 percent of each LH2 tank barrel, is assumed to be covered with TPS and associated TPS support structure. Only a portion of each LH2 tank is covered with TPS and support structure because the LH2 tanks are located on either side of the RLV payload bay.

As the tank barrel radii are increased over their baseline values, the tank barrel weight will increase. These barrel weight increases are then subtracted from corresponding reductions in TPS support structure weight to provide an estimate of the net structural weight change. Because the membrane tanks and tension webs are sized using only strength criteria (i.e., buckling, non-optimums, subsystem attachments, etc. are not included), the computed weight increases in the tanks may be smaller than the actual tank weight increases. In addition, no minimum gage constraints were imposed in this analysis.

The baseline dual-lobe LOX tank barrel geometry and associated dimensions are shown in figure 3. The LOX tank cross-section has a linear variation from a circular cross-section $(\mathrm{h} / \mathrm{r}=0)$ at the forward ring frame, to a cross-section with $\mathrm{h} / \mathrm{r}=0.42$ at the aft ring frame. The parameter $\mathrm{h}$, shown in figure 3 , is defined as the perpendicular distance from the center of a circular lobe to the vertical plane of symmetry. The baseline quad-lobe LH2 tank barrel geometry and associated dimensions are also shown in figure 3. The parameters $\mathrm{hx} / \mathrm{r}$ and hy/r have similar definitions to those given above for the LOX tank, and are both assumed to vary linearly along the tank length. 

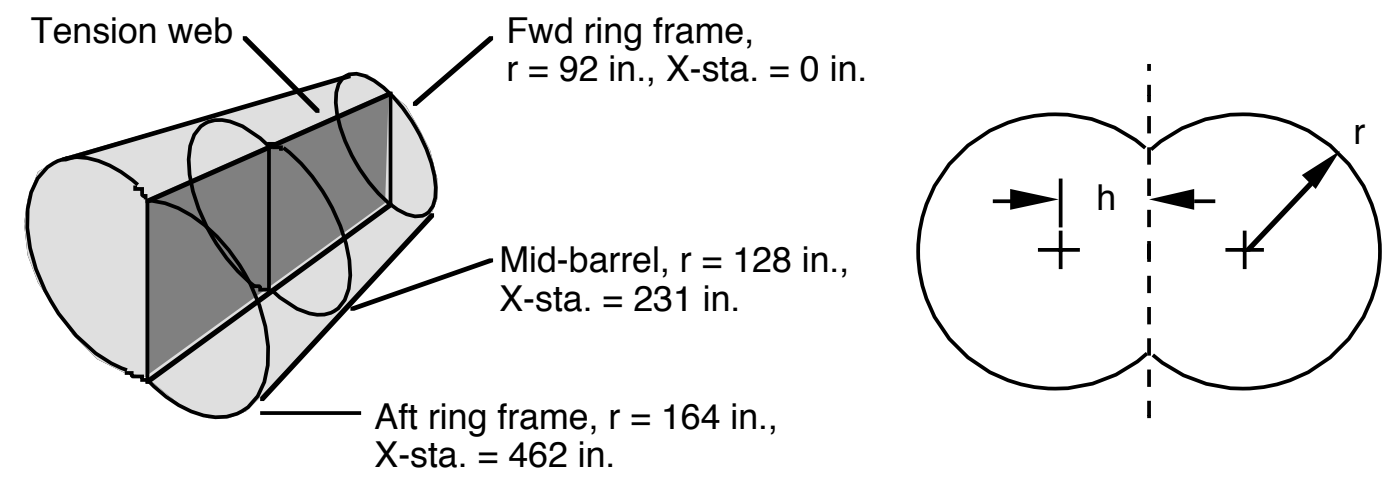

Figure 1: Dual-lobe LOX tank geometry
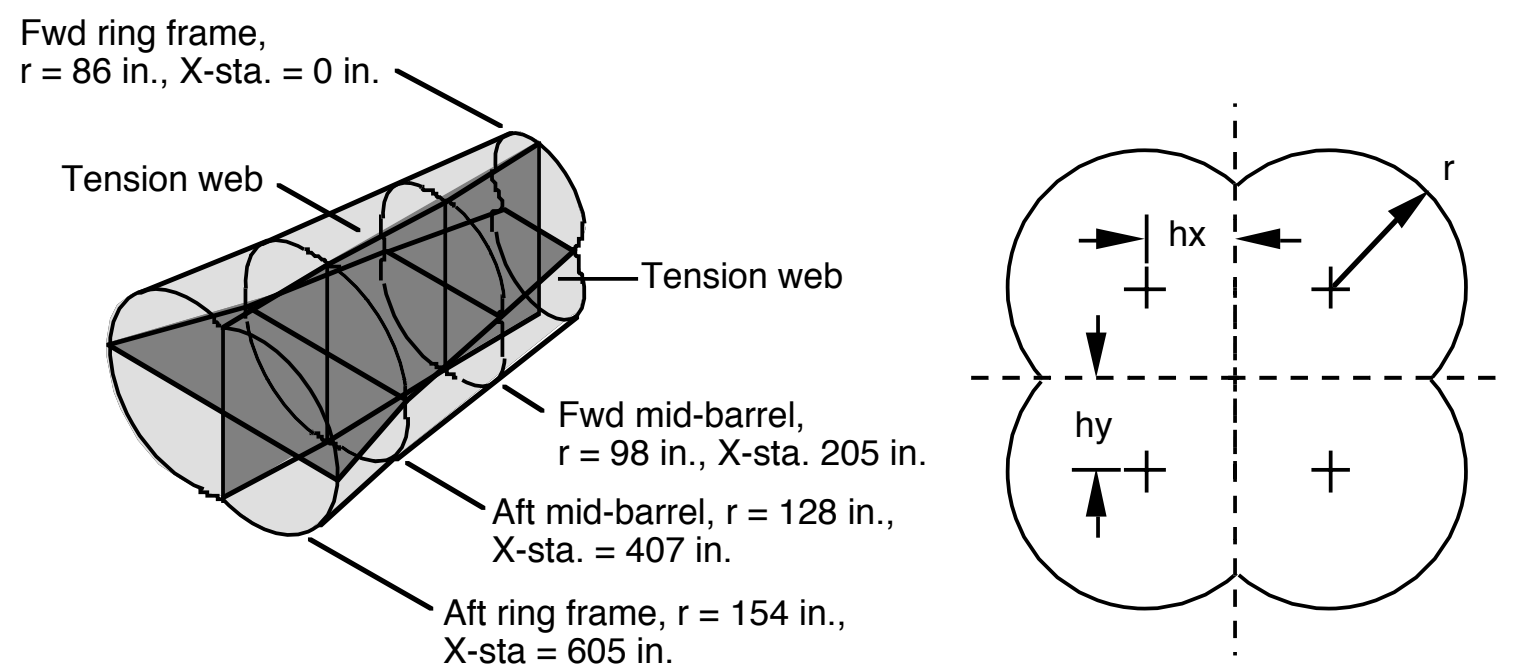

Fiaure 2: Quad-lobe LH2 tank geometry

Figure 3. Tank geometries.

The pressure in the forward half of the LOX tank is assumed to be $30 \mathrm{psig}$ at room temperature. The pressure in the aft half of the LOX tank varies linearly from $30 \mathrm{psig}$ at the mid-barrel station to $55 \mathrm{psig}$ at the aft ring frame station to account for LOX head pressure. The temperature in the aft half of the LOX tank is assumed to be -297 degrees F and the temperature in the forward half is assumed to be nominally 70-degrees $\mathrm{F}$ to account for hot ullage gas. The LH2 tank is pressurized to 40 psig at $-423 \mathrm{deg}$ F. Material properties for the LH2 and LOX tank analyses are nominal properties for Al-Li 2195 at the corresponding tank temperature. These properties are: density of 0.098 $\mathrm{lb} / \mathrm{in}^{3}$; yield strengths of $66 \mathrm{klb} / \mathrm{in}^{2}$ at room temperature, $76 \mathrm{klb} / \mathrm{in}^{2}$ at $-297 \mathrm{deg} \mathrm{F}$, and $81 \mathrm{klb} / \mathrm{in}^{2}$ at $-423 \mathrm{deg} \mathrm{F}$.

The baseline dual-lobe LOX tank barrel has a computed volume of $18515 \mathrm{ft}^{3}$. The linearized sensitivity of the tank barrel volume to a change in the LOX tank radius is $+286 \mathrm{ft}^{3} / \mathrm{inch}$. Since the entire LOX tank barrel is covered with TPS, the sensitivity of the corresponding reduction in TPS support structure (at $\left.1.8 \mathrm{lb} / \mathrm{ft}^{3}\right)$ is $-514 \mathrm{lb} / \mathrm{inch}$. The combined weight of the baseline strength-sized tank barrel and tension web is $3417 \mathrm{lb}$. The sensitivity of the computed barrel weight to changes in the tank radius is $+52 \mathrm{lb} / \mathrm{inch}$. Each of these sensitivities is computed for increases in LOX tank radius from 2 to 6 inches over the baseline design values.

The baseline quad-lobe LH2 tank barrel has a computed volume of $23621 \mathrm{ft}^{3}$. The linearized sensitivity of the tank barrel volume to changes in the LH2 tank radius is $+420 \mathrm{ft}^{3} / \mathrm{inch}$. Since 61 percent of each LH2 tank barrel is assumed covered with TPS, the sensitivity of the corresponding reduction in TPS support structure (at $1.8 \mathrm{lb} / \mathrm{ft} 3)$ is $-461 \mathrm{lb} / \mathrm{inch}$. The combined weight of the baseline strength-sized tank barrel and tension web is $3985 \mathrm{lb}$. The 
sensitivity of the computed barrel weight to changes in the tank radius is $+70 \mathrm{lb} / \mathrm{inch}$. Each of these sensitivities is computed for increases in LH2 tank radius from 2 to 6 inches over the baseline design value.

The vehicle volumetric packaging efficiency is defined as the primary tankage volume divided by the quantity (vehicle OML volume - payload volume). For the baseline vehicle, the packaging efficiency is equal to 70.1 percent, and the quantity (vehicle OML volume - payload volume) is equal to $142650 \mathrm{ft} 3$. Thus, the tankage (barrels and domes) volume is equal to $99998 \mathrm{ft} 3$. For a 1 inch increase in both the LOX and LH2 tank barrel radii, the total increase in tank barrel volume is $+(286+2 \times 420) \mathrm{ft} 3$, or $+1126 \mathrm{ft} 3$. This corresponds to an increase in the packaging efficiency of +0.789 percent. Since the vehicle empty weight sensitivity is assumed equal to $-2300 \mathrm{lb}$ of empty weight per percent increase in packaging efficiency, a 1 inch increase in the LOX and LH2 tank barrel radii results in a vehicle empty weight reduction of $-1815 \mathrm{lb}$.

For a 1 inch increase in both the LOX and LH2 tank barrel radii, the total reduction in TPS support structure is $(514+2 \times 461) \mathrm{lb}$, or $1436 \mathrm{lb}$. The corresponding increase in tank barrel and tension web weight is $(52+2 \times 70)$ $\mathrm{lb}$, or $192 \mathrm{lb}$, for a net structural weight reduction of $1244 \mathrm{lb}$ per inch of tank barrel radial growth. As noted previously, the vehicle empty weight is assumed to decrease by 3.8 pounds for every pound of subsystem weight removed from the vehicle. Thus, a structural weight reduction of $1244 \mathrm{lb} /$ inch corresponds to a vehicle empty weight reduction of $4727 \mathrm{lb} /$ inch. The combined vehicle empty weight reduction from both packaging efficiency increases and structural weight reductions is $6542 \mathrm{lb}$ of empty weight per inch of tank barrel radial growth.

\section{Weight Reduction Due To Conformal Tanks}

Potential reductions in vehicle system weight can be achieved by decreasing the distance between vehicle OML and tank OML. The potential of using conformal fuel tanks is also being investigated as a means to achieve vehicle empty weight savings. If conformal tanks (i.e., tanks that conform to the vehicle OML shape as shown in figure 4) are used, the volumetric efficiency of the tanks can be increased, and TPSS (and its associated weight) can be reduced. Conformal tanks have not been considered previously because they react internal pressure loads through bending as well as membrane loading, which is less structurally efficient than reacting pressure with pure membrane loading, as is done in cylindrical tanks. If only tank skin weights are compared, conformal tanks do not appear to be weight competitive with cylindrical or lobed tanks. However, when the increase in vehicle volumetric packaging efficiency, the reduction in TPSS weight, and potential reduction or elimination of tank longitudinal lobe joints are considered, a conformal tank/TPS system potentially could be lighter that a multi-lobed tank/TPS system.

\section{LOX Tank Geometry LH2 Tank Geometry}

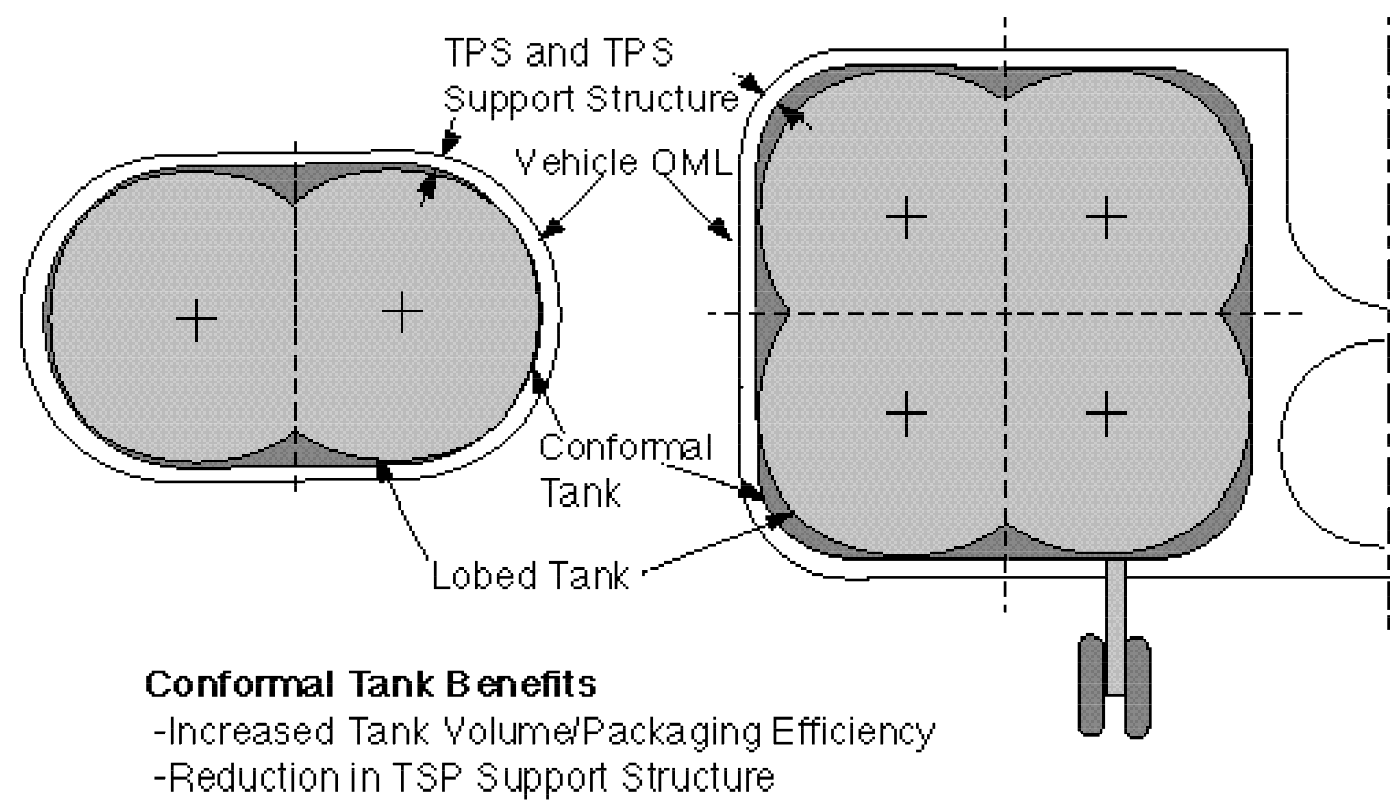

Figure 4. Benefit of conformal cryogenic tanks. 
In this trade study, the four conformal tank concepts shown in Figure 5 were studied. In each concept, the tank wall is a sandwich structure consisting of quasi-isotropic graphite composite face sheets and a five-pound-per-cubic-foot core material. Concept 1 is stiffened with axial tension webs, Concept 2 with transverse tension webs, Concept 3 with ring frames and tension ties, and Concept 4 with orthogrid stiffeners and tension ties. For each concept, geometric parameters (such as ring frame spacing, the number and spacing of tension ties or webs, tank corner radius and flat lengths) and internal pressure loads are varied and the structure is optimized using a finite element based optimization procedure (Martin, 1996) in the Engineering Analysis Language (EAL) finite element analysis system (Whetstone, 1983). The optimization is performed using a sequential linear programming procedure.

For each structural concept, a finite element model of a quarter section (150-in. by 150 -in.) of a symmetric cryogenic tank was constructed. The tank wall was modeled with isotropic-honeycomb-sandwich generalized plate elements which have both membrane and bending capability, tension webs were modeled using membrane elements, tension ties were modeled using rod elements, and ring frames and orthogrid stiffeners were modeled using I-beam elements. Both the facesheet thickness and the honeycomb core height of the plate elements, skin thicknesses of the web elements, cross-sectional area of the rod elements, and I-beam dimensions were varied to obtain an optimum

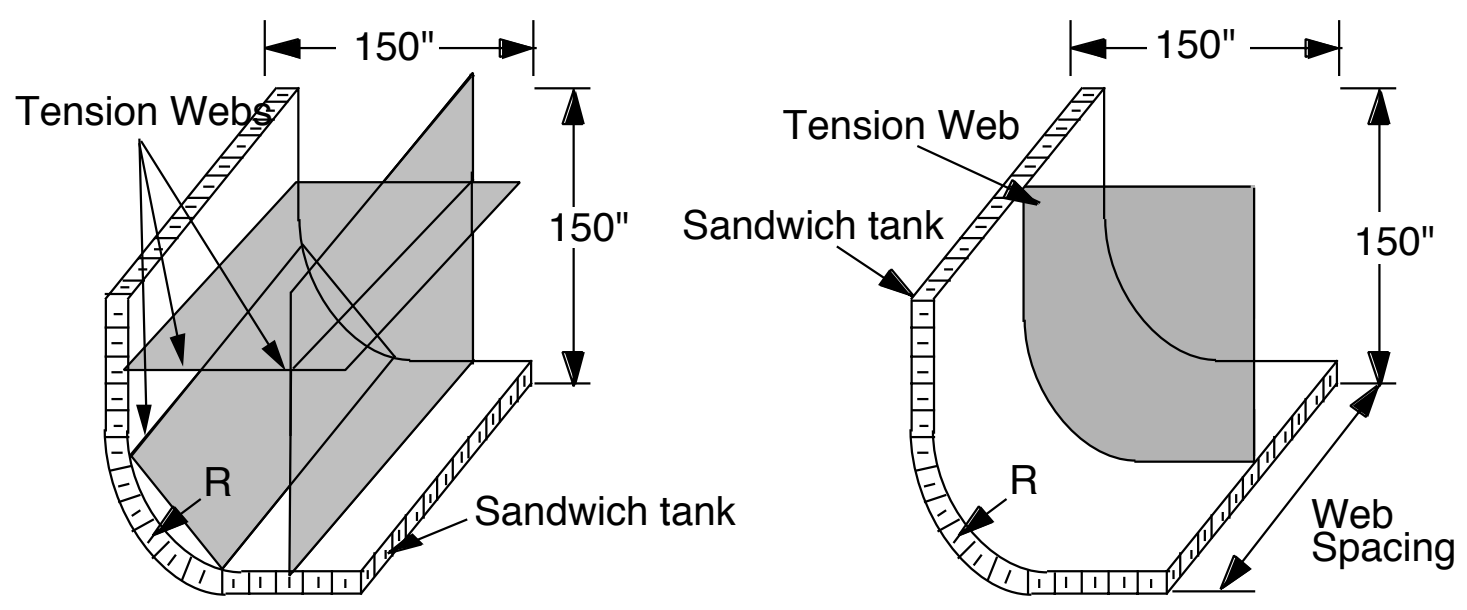

Concept 1

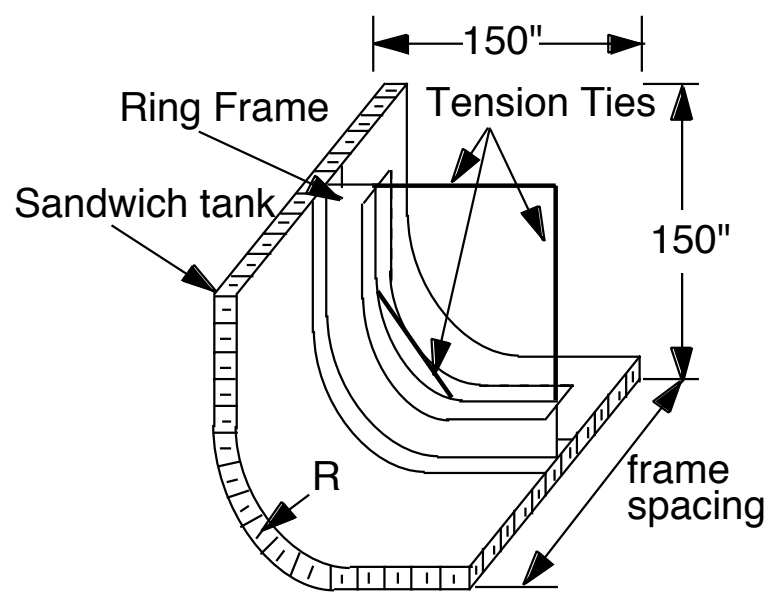

Concept 3
Concept 2

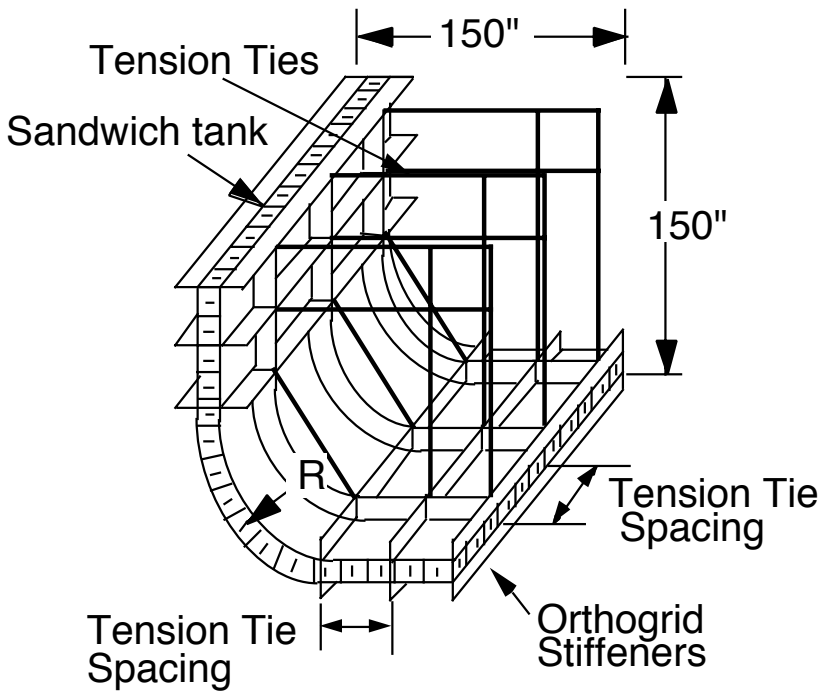

Concept 4

Figure 5. Conformal tank structural concepts. 


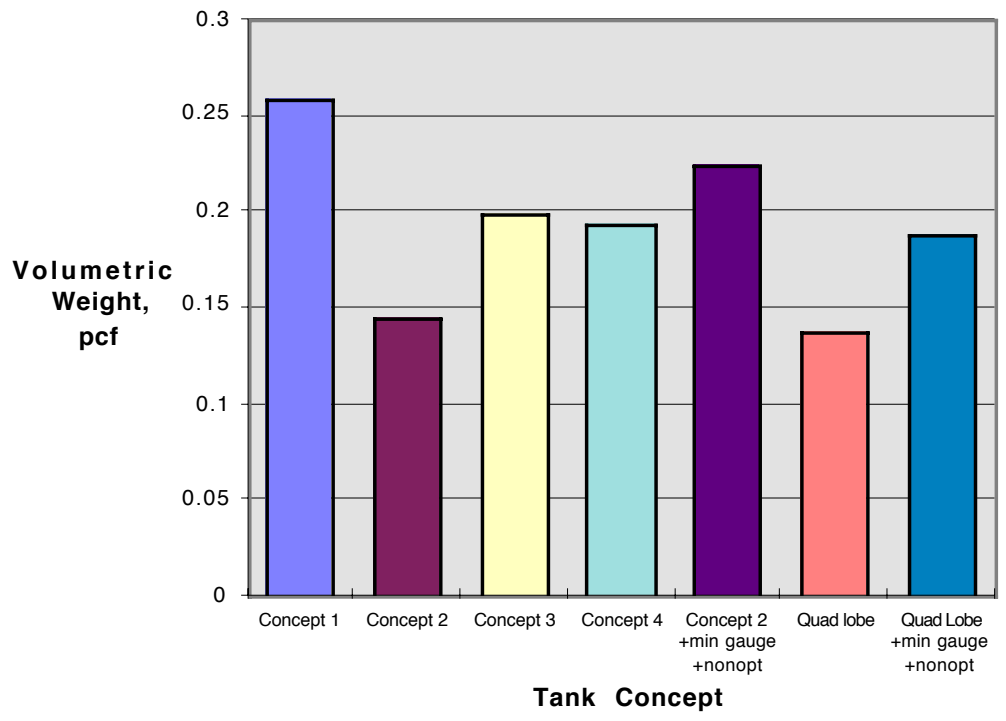

FIGURE 6. Volumetric weight comparisons for each concept for the case with a 25 -in. corner radius and an internal pressure of 20 psi.

(minimum weight) structure. In order to provide a nominal degree of cryogenic insulation, a 1-inch thick minimum gage was used for the honeycomb core. Geometric parameters particular to each concept (such as tank corner radius, internal pressure, ring frame spacing, tension tie spacing, and tension web spacing) were varied and structural optimization was performed to obtain a minimum weight solution. Volumetric weights (which did not include any non-optimum factors) were calculated for each concept by dividing its sized mass by its corresponding enclosed volume.

The volumetric weights (tank mass/tank volume) for concepts 1 through 4 , as well as for a sandwich wall quadlobed tank are shown in Figure 6. The quad-lobed tank has 100-inch radius lobes contained in a 150-inch square area. The conformal tank concepts all have a 25-inch corner radius. All tanks were sized for an internal pressure of 20 psi. The volumetric weights are given for all of the concepts considering no facesheet minimum gauge constraints or non-optimum weights. Volumetric weights were also calculated for concept 2 and the quad-lobe tanks with minimum gage constraints (6-ply sandwich facesheet and 4-ply tension web thicknesses) and a non-optimum factor applied for tension web attachment (an addition of $25 \%$ of the calculated tension web mass).

Of the conformal concepts studied, concept 2 resulted in the lightest weight tank. In addition, the weight of concept 2 compares very favorably with the weight of a sandwich wall quad-lobe tank for both theoretical sizing and when minimum gage constraints and weight non-optimums are considered.

\section{RLV Airframe Structural Weights}

Structural weights for vehicle performance sizing are being determined using a combination of preliminary structural design techniques in combination with contractor supplied non-optimum weight information. Contractor supplied geometry is input to the PATRAN/NASTRAN finite element modeling system and the NASTRAN design optimization procedure is used for sizing. After the optimization is completed for components, the calculated structural weight is used as reference input data to develop parametric equations, which are used in the weights model of the vehicle performance analysis/sizing code. Currently, sizing/weights data have been generated for the following components: engine thrust structure; LH2 tank; LH2 tank frames; lobed-tank Y joints; and main wing (see figure 2). Representative results for two component sizings are presented. 

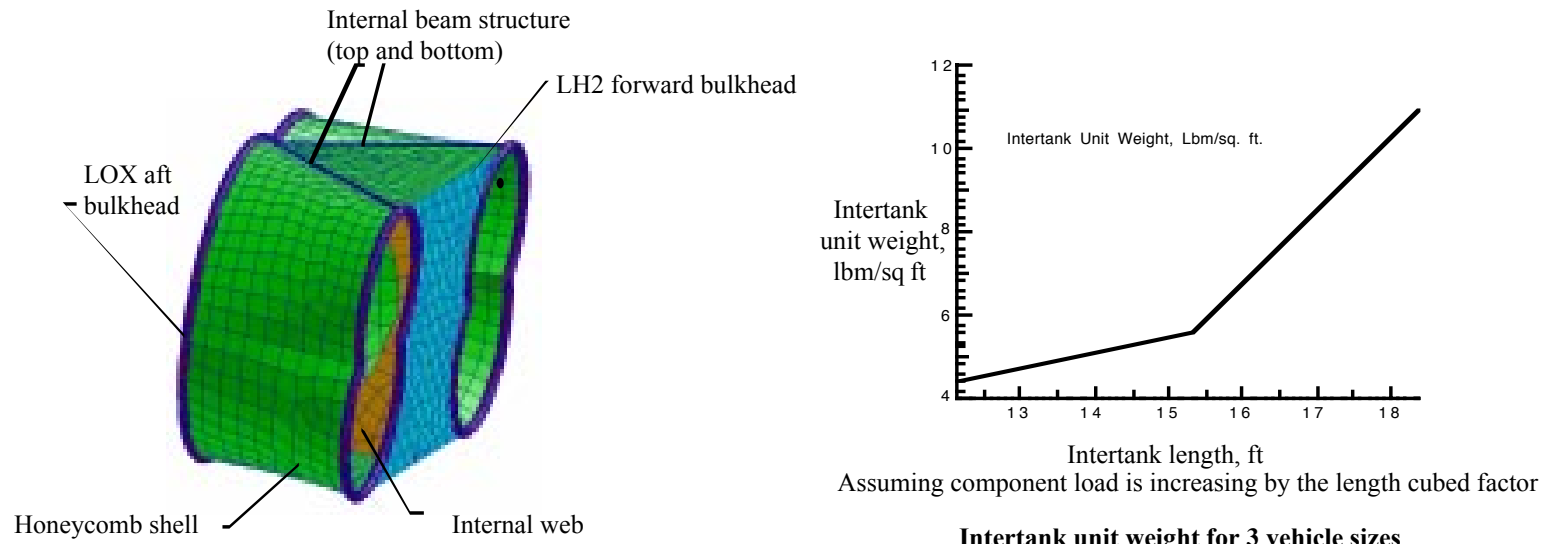

Intertank unit weight for 3 vehicle sizes

Intertank structural arrangement

Figure 7. Intertank model and unit weights.

\section{Intertank}

A composite sandwich intertank is used to connect the aft bulkhead of the vehicle LOX tank to the forward bulkhead of the vehicle LH2 tanks (see figure 7). The sandwich structure is assumed to be IM7/977-2 composite facesheets (with a 4-ply per facesheet minimum gage) on a $5.5 \mathrm{lbm} / \mathrm{ft}^{3}$ honeycomb core. The objective of this study was to calculate the change in intertank structural weight as a function of intertank length and vehicle size. Weights of the LOX aft bulkhead and LH2 forward bulkhead are included in the intertank weight. NASTRAN optimization was used to determine the thickness of 0,90 , and \pm 45 -degree laminae in the facesheets, honeycomb core height and structural weights. The primary loading for the intertank is a compressive force induced by axial acceleration of the vehicle; resulting in a thrust load of 4.48 million $\mathrm{lbf}$ for the reference size. Strength and general stability failure modes are used as constraints during the optimization analysis. The reference vehicle size is based on a configuration having an estimated 2.6 million lbf liftoff weight and an intertank structure that is 15.3 feet in length.

The calculated intertank unit weight (intertank weight divided by the surface area of the intertank barrel section) is calculated to be $5.6 \mathrm{lbm} / \mathrm{sq}$. ft. at the baseline size, including bulkheads. This weight includes a 1.5 non-optimum factor to account for additional load conditions, fittings, pad-ups, and other items not included in the FEM definition of the structure. The weight breakdown is $27 \%$ for the forward bulkhead (LOX aft bulkhead), $20 \%$ for the aft bulkhead (LH2 forward bulkhead), 1\% for an internal honeycomb web, $6 \%$ for internal beam structure, and $46 \%$ for the honeycomb shell. The compressive load applied to the intertank is assumed to scale with the volume of the vehicle and the intertank length is scaled in proportion to vehicle length. Figure 7 also shows the variation of intertank unit weight as a function of intertank length for three intertank lengths.

\section{Ring Frames}

A composite honeycomb tank is assumed to be reinforced with ring frames, which serve to increase buckling resistance, and to distribute aeroshell (consisting of TPS) aerodynamic loading into the LH2 tank skin structure. The dominant component loads are compressive forces from TPS transmitted aerodynamic pressures. The three pressure levels analyzed are $0.5,1.0$ and $2.0 \mathrm{psi}$. The pressure is assumed uniform over the aeroshell area defined by the frame spacing length and the outer frame circumference. The frames are sized assuming uniform section properties for the sandwich ring. Each frame is constructed of IM7/977-2 composite facesheets (with a 4-ply per facesheet minimum gage) on a $5.5 \mathrm{lbf} / \mathrm{ft}^{3}$ honeycomb core, and a typical frame in the mid-section of the LH2 tank was sized. Lamina strength and frame stability constraints are imposed to determine component sizes. NASTRAN optimization is used to determine the thickness of 0,90 , and \pm 45 -degree laminae in the ring frame facesheets and thus weights for various assumptions of aerodynamic load and ring frame spacing. For each pressure loading of .5, 1.0, and $2.0 \mathrm{psi}$, frame spacings of 18., 25., and 50. inches were studied.

The ring frame weights, per square foot of LH2 tank surface, are shown parametrically for various ring frame spacings in figure 8 . The weights do not include any non-optimum factors. As frame spacing is increased, the weight for a 


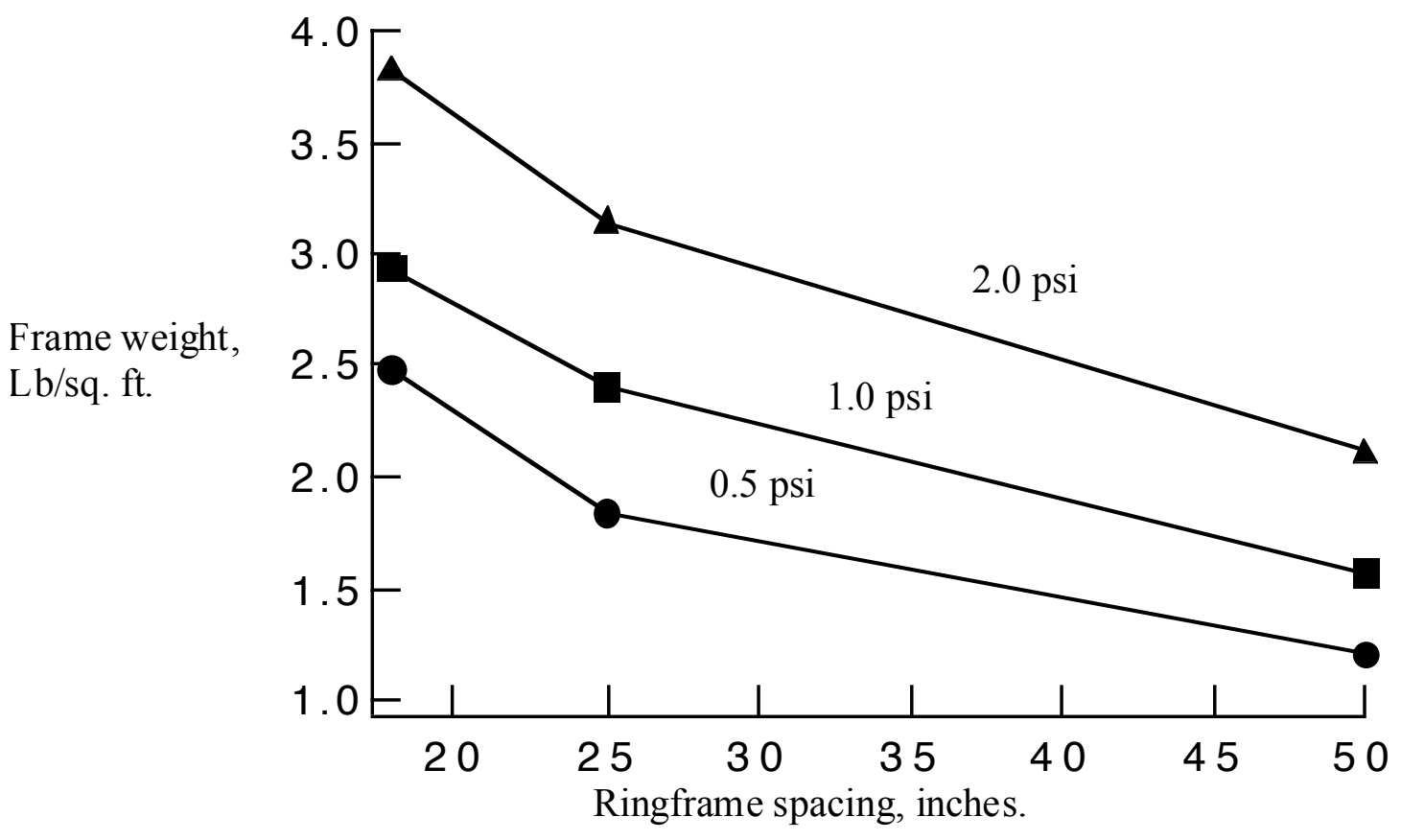

Figure 8. Parametric ring frame weights.

single frame increases but at a rate such that the corresponding frame weight per square foot of LH2 tank surface area decreases.

\section{Multi-lobe Hydrogen Tank Instability Analysis and Sizing}

Dual-lobe and quad-lobe hydrogen tanks are being considered for the RLV. The purpose of this study is to increase the fidelity of structurally sizing for dual-lobe and quad-lobe hydrogen tanks in order to discriminate between the structural performance and weight of the two concepts. This is accomplished by assessing the effect of a potentially worst-case load condition on the structural weight for both the dual-lobe and quad-lobe cryogenic tanks. Instability response of both tank concepts is evaluated to determine the degree of stiffening (either using frames or longerons) needed to resist a buckling failure. A composite sandwich tank structure is assumed for comparing the two tank structural concepts. The following assumptions and analysis inputs are used for the study:

1) Sandwich face sheets are IM7/977-2 composite material bonded to a $5.5 \mathrm{lbm} / \mathrm{ft}^{3}$ honeycomb core with a minimum thickness of 1 inch.

2) Sizing based on strength limits of the composite facesheets.

3) Neither the frames nor longerons are incorporated into the buckling analysis, but are accounted for in the tank weight.

4) Internal tension ties are modeled as discrete rods at each node location with the dual-lobe tank concept having one plane of ties and the quad-lobe concept having two mutually orthogonal planes. The ties are sized for both strength and deflection criteria.

5) Bulkheads, both fore and aft, are modeled as rigid ring frames for purposes of load introduction.

6) Optimization is based on sizing the thickness of individual [0/+-45/90] laminae with the core height also included as an optimization variable.

Analytical results are based on a LOX forward RLV configuration with three worst case loading scenarios:

1) Proof Pressure: 34 psi internal pressure with a F.S. of 1.5, yielding a total applied pressure of 51 psi.

2) LOX tank fueling: 5psi internal pressure with a thrust load (including 1.4 F.S.) of 1.47 million lbf.

3) Landing loads: 5psi internal pressure with an induced landing bending moment (including 1.4 F.S.) of 75.6 million in-lbs. 


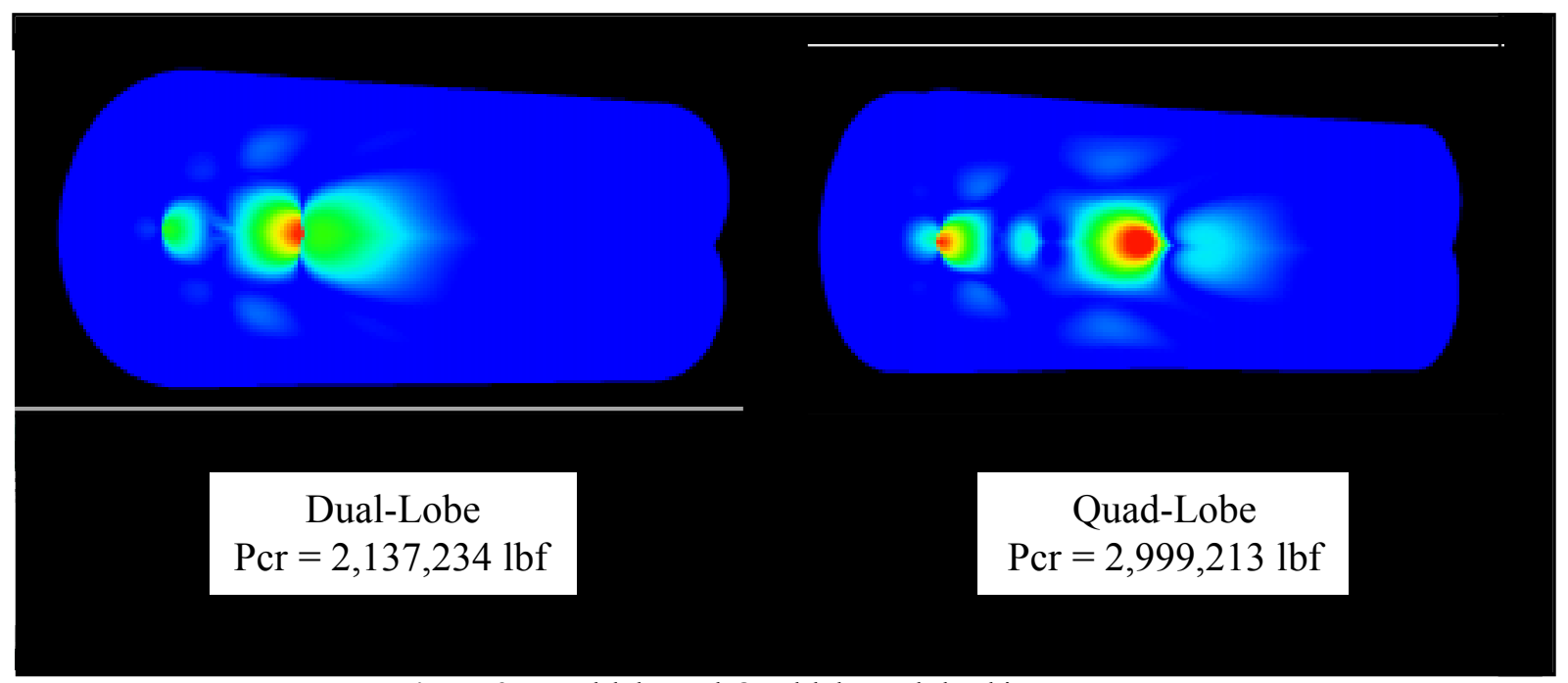

Figure 9. Dual-lobe and Quad-lobe tank bucking response.

Buckling analyses were conducted with no ring frames or stringers attached to the tanks. The primary bifurcation modes for the two tanks, shown in figure 9, occur near the tank lobe cusps. The smallest distance between half waves is approximately 48 inches. The buckling load for the quad-lobe tank is substantially higher than that for the dual-lobe tank. However, the designs were not buckling critical at the optimum design.

As-sized weights for the two concepts are given in Table 1. Areal and volumetric weights were calculated for both tank concepts, including a 1.5 non-optimum factor, and are given in Table 2. The non-optimum factor accounts for load conditions not considered, fittings, pad ups and other items not included in the finite element model definition of the tank components.

TABLE 1. Dual-Lobe and Quad-Lobe Tank Weights.

Dual-Lobe Tank

Quad-Lobe Tank

\begin{tabular}{|c|c|c|c|c|}
\hline $\begin{array}{l}\text { Total Tank Surface } \\
\text { Area, } \mathrm{ft}^{2}\end{array}$ & \multicolumn{2}{|c|}{5,579} & \multicolumn{2}{|c|}{6,146} \\
\hline $\begin{array}{l}\text { Total Tank Volume, } \\
\mathrm{ft}^{3}\end{array}$ & \multicolumn{2}{|c|}{28,983} & \multicolumn{2}{|c|}{31,376} \\
\hline Component & Weight, lbm & $\%$ of total & Weight, lbm & $\%$ of total \\
\hline Skins & 7620 & 53 & 6296 & 44 \\
\hline Frames & 3852 & 27 & 4200 & 30 \\
\hline Honeycomb Core & 2441 & 17 & 2689 & 19 \\
\hline Joints & 304 & 2 & 441 & 3 \\
\hline Tension Ties & 225 & 2 & 591 & 4 \\
\hline Total & 14,442 & 100 & 14,217 & 100 \\
\hline
\end{tabular}


TABLE 2. Tank Areal and Volumetric Weights.

\begin{tabular}{lcc} 
Areal and Volumetric Weights & Dual-Lobe & Quad-Lobe \\
\hline Areal, $\mathbf{l b m} / \mathbf{f t} \mathbf{2}$ & 3.88 & 3.47 \\
Volumetric, $\mathbf{l b m} / \mathbf{f t 3}$ & 0.75 & 0.68 \\
\hline
\end{tabular}

\section{Thermal Protection System Concepts Trade Study}

The primary objective of this study is to predict thermal protection system (TPS) and support structure weights for a RLV. These weights will be used in vehicle sizing studies and to compare alternative TPS concepts. The baseline concept for this study is the TPS design for the X-33. Predicted reentry heat loads for the RLV and a uniform pressure load are used to size the TPS components, including the insulation thickness, and the support structure.

Three different TPS and TPS support structure concepts, as shown in figure 10, were selected for comparison. The baseline X-33 concept consists of an outer honeycomb sandwich panel backed with encapsulated fibrous insulation and is supported at the corners by standoff supports. This concept places the pressure seal at the hot outer surface. The standoff supports are mounted to cross beams between cryogenic tank ring frames. The other two concepts use derivatives of a metallic TPS concept developed at NASA LaRC. The second concept uses the basic design of the LaRC Super Alloy Honeycomb design that has undergone extensive development and testing. The insulation for this concept is located between a hot honeycomb outer sandwich and a cooler honeycomb sandwich, which supports the panel. It has been modified to be compatible with an aeroshell configuration by using a lattice support structure between tank ring frames and strengthening the lower titanium honeycomb sandwich to carry the aerodynamic pressure loads. The static pressure seal is located between the cooler sandwich and the lattice and uses a RTV and Nomex felt pad combination similar to strain isolation pads of the space shuttle. An over hanging flap on the upper sandwich surface is used to reduce hot gas ingress into the gap between panels. The final concept uses a LaRC TPS panel concept mounted on a honeycomb sandwich TPS carrier plate (that spans the ring frames). Aerodynamic pressure loads are vented down to the carrier plate.

The support structure, which is attached to the ring frames, is sized to carry a 2-psi pressure load subject to stress and deflection constraints. The support structure has not been sized to carry vehicle loads. For the ring frame weight calculations, an average depth of 6 inches in regions adjacent to the tanks is assumed with deeper sections spanning between the tanks. The ring frames are not structurally optimized, and are assumed to be sandwich construction with 0.04 inch-thick quasi-isotropic graphite composite face sheets and a 0.5 in. honeycomb core for all TPS concepts. Ring frame lineal weights are calculated as a function of frame spacing. The structure spanning the ring frames is sized to meet stress and deflection constraints for the nominal 2 psi load. Stress calculations use a load

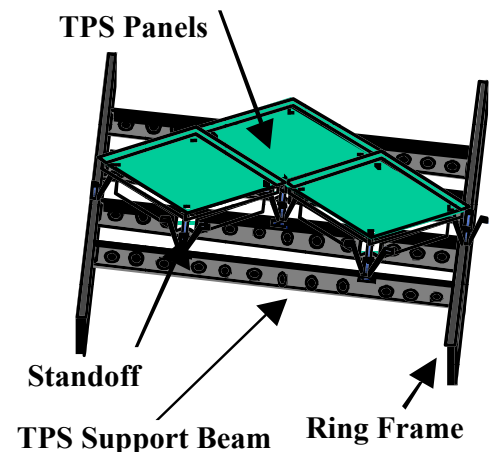

BF Goodrich X-33 Concept
(baseline)

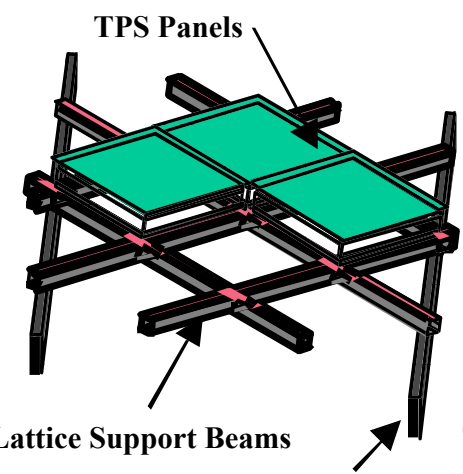

Ring Frame

LaRC Type TPS Panels with Lattice Seal \& Support Frames

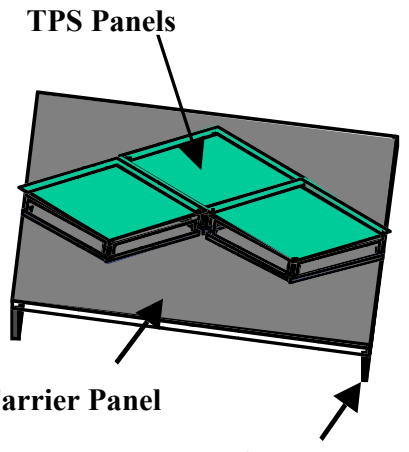

Ring Frame

Figure 10. TPS and TPS support structure concepts considered. 
factor of 1.5, and deflections are subject to a 1-percent-of-span waviness limit for the nominal 2 psi load. These criteria are used in the weight estimates for all the support structure. The lattice frames and carrier plate structures are sized for both titanium and graphite composite constructions, with appropriate minimum gages selected for the material systems. All honeycomb core is assumed to have a density of 5 pounds per cubic foot.

TPS weight calculations are based on nominal 18 inch square panels. Detailed weight statements for each concept have been generated based on consistent design requirements. The baseline TPS panel design and weights are taken from the X-33. The TPS insulation was thermally sized using heating rates predicted by the LaRC VAB for a nominal RLV trajectory. A one-dimensional transient finite element TPS analysis and sizing code is used to predict the required insulation thicknesses at various locations along the vehicle for each of the TPS concepts. Onedimensional thermal and weight models for each concept have been incorporated into the sizing code. The thermal models have undergone limited verification with more detailed two-dimensional models to ensure accurate modeling of heat shorts and overall system behavior. For the insulation sizing calculations, a composite sandwich tank, having 0.060 inch-thick face sheets and a 1.0 inch-thick honeycomb core, was assumed. The average temperature of the tank during entry is limited to a maximum of $350^{\circ} \mathrm{F}$.

Areal unit weights were calculated for both the TPS panels and the support structure. Support structure weights, calculated as a function of ring frame spacing for each concept, are shown in figure 11. The frame spacings selected were consistent with the 18-in. square TPS panels oriented in a diamond pattern over the vehicle. The minimum weight for all concepts occur at a ring spacing of 25.5 in., with the X-33 support structure concept being the lightest. The two carrier panel designs and the titanium lattice structure are all significantly heavier.

The results of the TPS panel sizing are illustrated in figure 12. These weights are for only the TPS panels, and total system weights would be the sum of the weights from the charts in figures 11 and 12. The X-33 TPS panels are shown to be significantly heavier than the other two concepts. This is primarily the result of excessive radiation heat shorts between the panels and near the supports of the current configuration. Some design changes to the X-33 concept could reduce the heat shorts and thus the weights. When the TPS panel and TPS support weights are added together, the LaRC TPS panel design supported on a lattice of support and sealing beams is approximately $0.2 \mathrm{lb} / \mathrm{ft}^{2}$ lighter than the X-33 baseline. The LaRC TPS supported on a carrier panel is approximately $0.3 \mathrm{lb} / \mathrm{ft}^{2}$ heavier than the $\mathrm{X}-33$ baseline design.

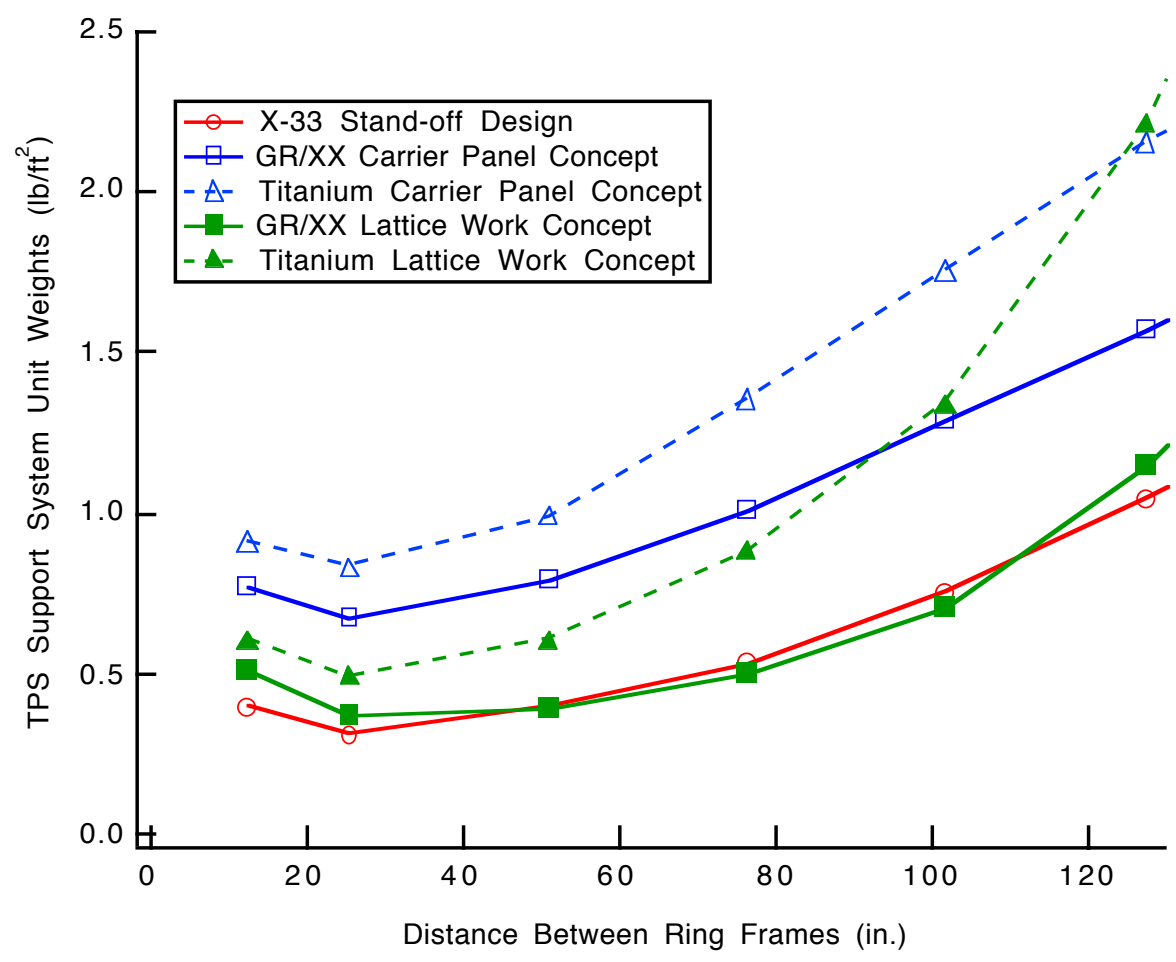

Figure 11. TPS support structure unit weights as a function of ring frame spacing. 


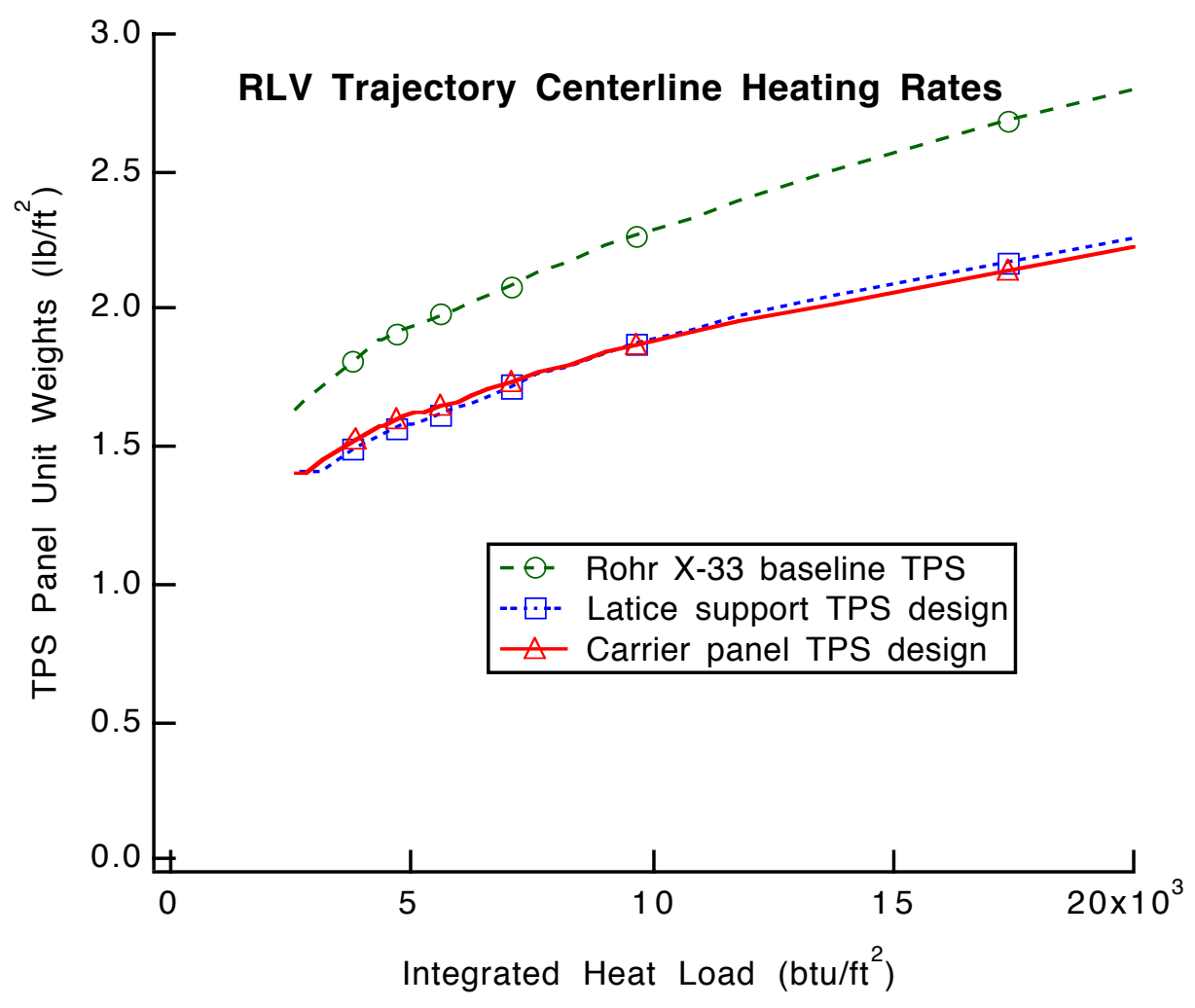

Figure 12. TPS panel weight as a function of total heat load.

\section{CONCLUDING REMARKS}

For highly integrated Single-Stage-to-Orbit Reusable Launch Vehicles, the total vehicle empty weight can be reduced by efficiently integrating the TPS, TPS support and tank system such that the distance between the tank and vehicle OMLs is minimized. Benefits (empty and GLOW weight reductions) are accrued from both increases in the vehicle packaging efficiency, and decreases in the amount of TPS support structure required.

Minimum weight systems may not necessarily have all components that are individually minimum weight. Although slightly heavier on a volumetric basis, conformal tanks have been shown to be weight competitive with multi-lobe tanks. However, because they conform so closely to the vehicle OML, conformal tanks will most likely require much less TPS support structure. Thus, depending on the weight efficiency of the TPS support structure, a conformal tank/TPS system can potentially weigh less than a lobed-tank/TPS system.

Determining the level of fidelity required to discriminate between structural concepts is critical for configuration- and airframe-level trade studies. Sizing relations which take into account major parameters such as component length, surface area, volume, induced loading, etc. have been developed for major RLV airframe structural components and incorporated into vehicle sizing analyses. In some instances, further increases in analysis fidelity are required to discriminate between concepts. For example, dual-lobe and quad-lobe tanks have very similar sizing and areal weights using the preliminary methods. However, a more refined finite element model analysis showed the buckling performance of the two tanks to be substantially different. When a more comprehensive set of load cases, design criteria (that include tank stability), and better weight fidelity (including non-optimums) are generated for vehicle sizing, the increased buckling capability of the quad-lobe geometry may result in that being the preferred concept.

The weights of two alternative concepts for an aeroshell type TPS/TPS support have been compared to the baseline X-33 design. One concept, a LaRC TPS panel design supported on a lattice of support and sealing beams, was found to be on the order of $0.2 \mathrm{lb} / \mathrm{ft}^{2}$ lighter than the X-33 baseline, and the other, a carrier panel design for the TPS, 
was found to be about $0.3 \mathrm{lb} / \mathrm{ft}^{2}$ heavier than the $\mathrm{X}-33$ baseline design. The two alternative design concepts of this study use TPS panels and support structure that are probably more complex and costlier then the X-33 baseline, but they offer improved damage tolerance and sealing to hot gas ingress. While these weights are preliminary, they demonstrate that there are design alternatives for an aeroshell TPS systems that can be weight competitive with the $\mathrm{X}-33$ design.

\section{ACKNOWLEDGMENTS}

The authors would like to acknowledge Mr. Jeff Cerro, Lockheed Martin for his performance of the RLV Airframe Structural Weights trade study.

\section{REFERENCES}

Cook, S. A., "The X-33 Advanced Technology Demonstrator", AIAA-96-1195, April 1996.

Martin, C. J., Jr., "Documentation for a Structural Optimization Procedure Developed Using the Engineering Analysis Language (EAL)", NASA Contractor Report 201632, October 1996.

Whetstone, W. D., "EISI-EAL Engineering Analysis Reference Manual". Engineering Information Systems, Inc., July 1983.

Wu, K. C. and Lepsch, R. A., "Nontangent, Developed Contour Bulkheads for a Wing-Body Single Stage Launch Vehicle". To be presented at the Thirty-seventh AIAA Aerospace Sciences Meeting and Exhibit, Reno, NV, January 11-14, 1999. 